ARTICLE

\title{
Identity and function of an essential nitrogen ligand of the nitrogenase cofactor biosynthesis protein NifB
}

Lee A. Rettberg ${ }^{1,5}$, Jarett Wilcoxen"2,4,5, Andrew J. Jasniewski (10 1,5, Chi Chung Lee', Kazuki Tanifuji1, Yilin Hu (1) ${ }^{1 凶}$, R. David Britt (1) ${ }^{2 凶}$ \& Markus W. Ribbe (i) ${ }^{1,3 凶}$

NifB is a radical S-adenosyl-L-methionine (SAM) enzyme that is essential for nitrogenase cofactor assembly. Previously, a nitrogen ligand was shown to be involved in coupling a pair of $\left[\mathrm{Fe}_{4} \mathrm{~S}_{4}\right]$ clusters (designated $\mathrm{K} 1$ and $\mathrm{K} 2$ ) concomitant with carbide insertion into an $\left[\mathrm{Fe}_{8} \mathrm{~S}_{9} \mathrm{C}\right]$ cofactor core (designated $\mathrm{L}$ ) on NifB. However, the identity and function of this ligand remain elusive. Here, we use combined mutagenesis and pulse electron paramagnetic resonance analyses to establish histidine-43 of Methanosarcina acetivorans NifB ( $\mathrm{MaNifB})$ as the nitrogen ligand for $\mathrm{K} 1$. Biochemical and continuous wave electron paramagnetic resonance data demonstrate the inability of MaNifB to serve as a source for cofactor maturation upon substitution of histidine- 43 with alanine; whereas $x$-ray absorption spectroscopy/extended $\mathrm{x}$-ray fine structure experiments further suggest formation of an intermediate that lacks the cofactor core arrangement in this MaNifB variant. These results point to dual functions of histidine-43 in structurally assisting the proper coupling between $\mathrm{K} 1$ and $\mathrm{K} 2$ and concurrently facilitating carbide formation via deprotonation of the initial carbon radical.

\footnotetext{
${ }^{1}$ Department of Molecular Biology and Biochemistry, University of California, Irvine, CA 92697-3900, USA. ${ }^{2}$ Department of Chemistry, University of California, Davis, CA 95695, USA. ${ }^{3}$ Department of Chemistry, University of California, Irvine, CA 92697-2025, USA. ${ }^{4}$ Present address: Department of Chemistry and Biochemistry, University of Wisconsin, Milwaukee, WI 53211, USA. ${ }^{5}$ These authors contributed equally: Lee A. Rettberg, Jarett Wilcoxen,

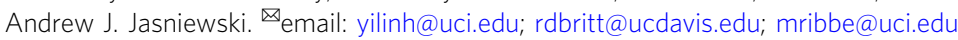


$\mathrm{N}$ ifB plays a key role in the biosynthesis of the active site of Mo-nitrogenase, an [( $R$-homocitrate $\left.)-\mathrm{MoFe}_{8} \mathrm{~S}_{9} \mathrm{C}\right]$ metallocofactor (designated M-cluster) that catalyzes the ambient conversion of dinitrogen $\left(\mathrm{N}_{2}\right)$ to ammonia $\left(\mathrm{NH}_{3}\right)^{1-6}$. A member of the radical $S$-adenosyl-L-methionine (SAM) enzyme family ${ }^{7,8}, \mathrm{NifB}$ is a monomeric protein carrying three $\left[\mathrm{Fe}_{4} \mathrm{~S}_{4}\right]$ clusters: ${ }^{9-12}$ one, designated the SAM-cluster, is ligated by a canonical CxxxCxxC motif and coordinates the SAM-binding $\left[\mathrm{Fe}_{4} \mathrm{~S}_{4}\right]$ cluster; the other two, designated the K-cluster, are ligated by a number of conserved ligands and supply the full complement of iron $(\mathrm{Fe})$ atoms for the biosynthesis of an $8 \mathrm{Fe}$ precursor to the mature cofactor. Previous studies of the NifB proteins from Azotobacter vinelandii and Methanosarcina acetivorans have led to the proposal that NifB utilizes a unique, radical SAM-dependent mechanism for carbide insertion concomitant with the transformation of the $\mathrm{K}$-cluster to an $\left[\mathrm{Fe}_{8} \mathrm{~S}_{9} \mathrm{C}\right]$ cluster (designated the Lcluster), which represents both an $8 \mathrm{Fe}$ precursor and an all-Fe core of the M-cluster ${ }^{13-16}$. This process begins with an $\mathrm{S}_{\mathrm{N}} 2$-type transfer of a methyl group from a SAM molecule to the K-cluster (Supplementary Fig. 1a, (1), and it is followed by hydrogen abstraction of the methyl group by a $5^{\prime}$-deoxyadenosyl $\left(5^{\prime}\right.$-dA $\left.\bullet\right)$ radical that is derived from the homolytic cleavage of a second SAM molecule (Supplementary Fig. 1a, (2)). The resultant methylene radical then undergoes further deprotonation/dehydrogenation to yield a $\mu_{6}-$ coordinated interstitial carbide concomitant with the radicalchemistry-based coupling and rearrangement of the two $\left[\mathrm{Fe}_{4} \mathrm{~S}_{4}\right]$ modules of the K-cluster (designated K1- and K2-cluster, respectively) into an $\left[\mathrm{Fe}_{8} \mathrm{~S}_{9} \mathrm{C}\right] \mathrm{L}$-cluster, which represents an all-Fe core of the M-cluster except for the substitution of one Fe atom for $\mathrm{Mo} /$ homocitrate at one end of the cluster (Supplementary Fig. 1a, (3)). Once generated, the L-cluster is passed from NifB onto NifEN, the next biosynthetic scaffold, where it is matured into a fully complemented M-cluster upon insertion of Mo and homocitrate by $\mathrm{NifH}$ prior to the delivery of M-cluster to its final binding site in NifDK, the catalytic component of Mo-nitrogenase (Supplementary Fig. 1a, (4) $)^{17-22}$.

The unique radical chemistry that occurs on NifB during the nitrogenase cofactor core assembly makes this protein an attractive subject of investigation, as knowledge in this regard will shed light on the unusual synthetic route to a high-nuclearity metallocofactor that is biologically important and chemically elusive. Previously, we have identified three sets of Cys ligands-three Cys per set-for the three $\left[\mathrm{Fe}_{4} \mathrm{~S}_{4}\right.$ ] clusters in $M$. acetivorans $\mathrm{NifB}$ (designated $M a \mathrm{NifB}$ ), namely, the SAM- cluster $\left(\mathrm{Cys}^{50}{ }^{5} \mathrm{Cys}^{54}\right.$, and $\left.\mathrm{Cys}^{57}\right)$, the K1-cluster $\left(\mathrm{Cys}^{30}, \mathrm{Cys}^{63}\right.$, and $\left.\mathrm{Cys}^{129}\right)$ and the K2-cluster $\left(\mathrm{Cys}^{264}\right.$, $\mathrm{Cys}^{274}$, and Cys $^{277}$ ) (Supplementary Fig. 1b, c) ${ }^{11}$. Further, we have established the coexistence of SAM- and K2-clusters as a prerequisite for methyltransfer and hydrogen abstraction to occur and pinpointed the K2-cluster as the site for methyl attachment and the subsequent hydrogen abstraction from the methyl group by a $5^{\prime}-\mathrm{dA} \bullet \mathrm{radical}^{11}$. Perhaps even more excitingly, using pulse EPR techniques, we have identified a nitrogen atom from a His residue as the fourth ligand for the K1-cluster that is lost upon coupling between the K1- and $\mathrm{K} 2$-clusters into an L-cluster ${ }^{11}$. This observation suggests an important role of the His/nitrogen ligand in generating the nitrogenase cofactor core (i.e., the L-cluster), particularly given the ability of His to undergo protonation/deprotonation, which either provides a release mechanism for the L-cluster onto the next biosynthetic apparatus or allows this residue to participate in the further deprotonation/dehydrogenation of the carbon radical to give rise to a central carbide. As such, it is crucial to identify this nitrogen ligand and probe its function in the process of nitrogenase cofactor core formation.

Here we use a combination of site-directed mutagenesis and pulse EPR spectroscopy to show that the $\mathrm{His}^{43}$ residue is the specific nitrogen ligand for the K1-cluster of $M a \mathrm{NifB}$. Our biochemical and
EPR analyses demonstrate the essential role of $\mathrm{His}^{43}$ in the formation of the nitrogenase cofactor core structure, although substitution of this residue with Ala does not impact early steps of carbide insertion leading to the initial hydrogen atom abstraction of the K2-associated methyl group. Our XAS/EXAFS analysis further reveals a shortened distance between the K1- and K2-clusters upon substitution of $\mathrm{His}^{43}$ with $\mathrm{Ala}$, as well as a further processing of these clusters into an intermediate between the $\mathrm{K}$ - and L-clusters upon incubation with SAM. These observations point to a dual function of $\mathrm{His}^{43}$ in positioning/orienting the $\mathrm{K} 1$-cluster relative to the K2-cluster for proper coupling and deprotonating the initial carbon radical for carbide formation.

\section{Results}

The identity of the histidine ligand of the K1-cluster. Sequence analysis of $M a \mathrm{NifB}$ revealed the presence of three highly conserved His residues, $\mathrm{His}^{28}$, $\mathrm{His}^{43}$ and $\mathrm{His}^{219}$, which could potentially serve as the nitrogen ligand for the K1-cluster on $\mathrm{NifB}^{M a}$ (Supplementary Fig. 1b). On the basis of this analysis, three $M a \mathrm{NifB}$ variants were heterologously expressed in Escherichia coli. Designated MaNifB $^{\mathrm{H} 28 \mathrm{~A}}, \mathrm{MaNifB} \mathrm{H}^{\mathrm{H} 3 \mathrm{~A}}$ and $M a \mathrm{NifB}^{219 \mathrm{~A}}$, respectively, each variant has one of the three conserved His residues substituted with Ala. Purified $M a N i f B$ variants, like their wildtype counterpart (designated $M a \mathrm{NifB}^{\mathrm{wt}}$ ), are monomers of $\sim 38 \mathrm{kDa}$ (Supplementary Fig. 2a). Moreover, upon FeS reconstitution, $M a \mathrm{NifB}^{\mathrm{H} 28 \mathrm{~A}}, \mathrm{MaN}$ ifB $^{\mathrm{H} 43 \mathrm{~A}}$, and $\mathrm{MaNifBH}{ }^{219 \mathrm{~A}}$ have Fe contents comparable to that of $M a N i f B$ wt, all of which carry three $\left[\mathrm{Fe}_{4} \mathrm{~S}_{4}\right]$ clusters (i.e., the SAM-, K1- and K2-clusters) per protein (Supplementary Fig. 2b). Thus, a loss of the His ligand does not seem to impact the ability of $M a \mathrm{NifB}$ to ligate any of the three $\left[\mathrm{Fe}_{4} \mathrm{~S}_{4}\right]$ clusters, likely due to the 3-Cyscoordination of these clusters that is sufficient to secure them in place.

To assess whether a nitrogen ligand is still present in these $M a \mathrm{NifB}$ variants, pulse EPR spectroscopy-specifically, three-pulse electron spin echo envelope modulation (3P-ESEEM) - was used to observe modulations to the time domain spectrum and corresponding peaks in the fast Fourier transformed (FFT) spectrum that can be assigned to the coordinating nuclei (Fig. 1; also see Supplementary Fig. 3). Consistent with our previous observation ${ }^{11}, \mathrm{MaNifB}{ }^{\mathrm{wt}}$ shows deep modulations in the time domain of the ESEEM spectrum (Fig. 1a, trace 1) and corresponding intensity between 0 and $6 \mathrm{MHz}$ in the FFT (Fig. 1b, trace 1), which have been previously assigned to the hyperfine and quadrupole couplings of a cluster-ligated ${ }^{14} \mathrm{~N}$ nucleus ${ }^{11}$. Similar modulations and intensities are present in the ESEEM spectrum and FFT of $M a \mathrm{NifB}^{\mathrm{K} 1}$, a variant carrying only the K1-cluster but no SAM- and K2-clusters (because of substitutions of the Cys ligands of the SAM- and K2-clusters with Ala ${ }^{11}$ ), affirming the previous assignment of the nitrogen ligand to the K1-cluster (Fig. 1a, b, trace 5). While similarly deep modulations and intensities are observed in the ESEEM spectra and FFTs of $M a \mathrm{NifB}^{\mathrm{H} 28 \mathrm{~A}}$ and $M a \mathrm{NifB}^{\mathrm{H} 219 \mathrm{~A}}$ (Fig. 1a, b, traces 2, 3), these features are clearly absent from the ESEEM spectrum and FFT of $M a N_{i f B}{ }^{H 43 A}$ (Fig. 1a, b, trace 4), suggesting $\mathrm{His}^{43}$ as the nitrogen ligand for the K1-cluster. To seek further support for this assignment, $M a \mathrm{NifB}^{\mathrm{K} 1-\mathrm{H} 43 \mathrm{~A}-}$ another $M a \mathrm{NifB}$ variant carrying only the Cys ligands of $\mathrm{K} 1$ along with a substitution of $\mathrm{His}^{43}$ with $\mathrm{Ala}$-was heterologously expressed in $E$. coli. The purified $M a \mathrm{NifB}^{\mathrm{K} 1-\mathrm{H} 43 \mathrm{~A}}$ demonstrates the same subunit composition as $M a \mathrm{NifB}^{\mathrm{K} 1}$, as well as the same Fe content that is consistent with the presence of one $\left[\mathrm{Fe}_{4} \mathrm{~S}_{4}\right]$ cluster (i.e., the K1-cluster) per protein upon FeS reconstitution (Supplementary Fig. 2a, b). However, contrary to $\mathrm{MaNifB}^{\mathrm{K} 1}$ (Fig. 1a, b, trace 5), $\mathrm{MaNifB}{ }^{\mathrm{K} 1-\mathrm{H} 43 \mathrm{~A}}$ does not show deep modulations and intensities in its ESEEM spectrum and FFT (Fig. 1a, b, trace 6), firmly establishing $\mathrm{His}^{43}$ as the nitrogen ligand that specifically coordinates the K1cluster. 

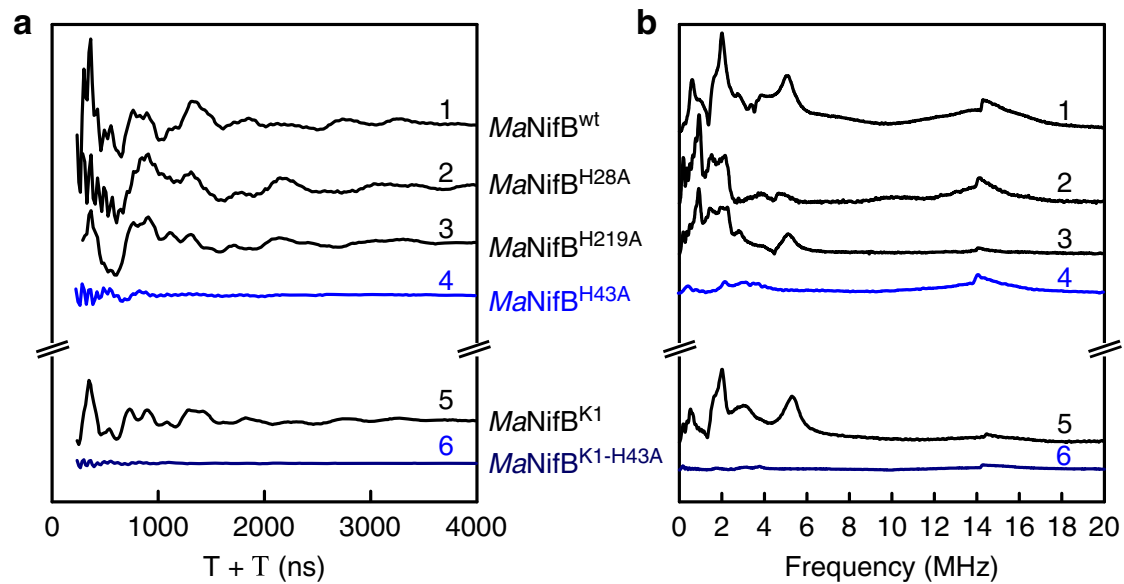

Fig. 1 Three-pulse ESEEM spectra of dithionite-reduced MaNifB proteins. a Time domain and (b) fast Fourier transformed (FFT) spectra of MaNifBwt (1), MaNifB H28A (2), MaNifB H219A (3), MaNifB H43A (4), MaNifB K1 (5) and MaNifB K1-H43A (6). The time domain spectra of the His-ligand containing samples (i.e., 1, 2, 3, and 5) have modulations from ${ }^{14} \mathrm{~N}$ that appear as peaks in the fast Fourier transformed (FFT) spectra between 1 and $6 \mathrm{MHz}$. The sharp modulations between 250 and $500 \mathrm{~ns}$ in the time domain and the resulting broad peak near $14 \mathrm{MHz}$ in the FFT are from nearby weakly coupled protons. The ESEEM spectra were recorded at $10 \mathrm{~K}, \tau=128-144 \mathrm{~ns}, \pi / 2=12 \mathrm{~ns}$, and $9.3366 \mathrm{GHz}$. The experiment was performed three times independently $(n=3$ independent samples), and representative results are shown in the figure. All protein samples have a concentration of $15 \mathrm{mg} \mathrm{mL}-1$. The CW EPR spectra of these dithionite-reduced MaNifB proteins are shown in Supplementary Fig. 3.
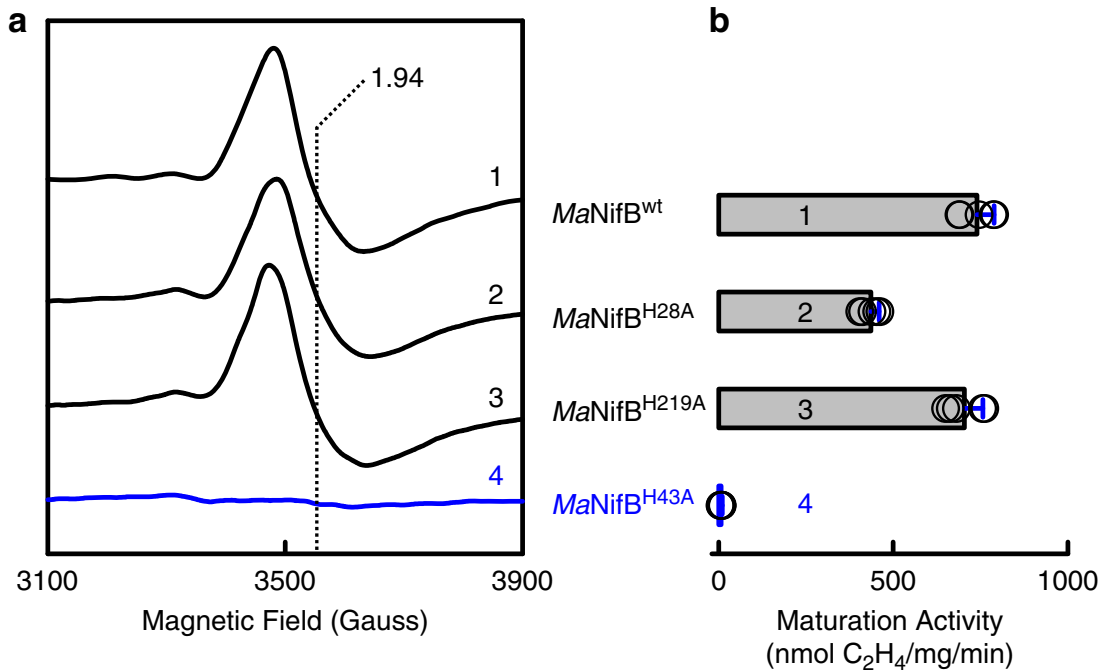

Fig. 2 Conversion of L-cluster to M-cluster on MaNifB proteins. a EPR spectra of IDS-oxidized MaNifBwt (1), MaNifB H28A (2), MaNifB H219A (3), and $\mathrm{MaNifB} H 43 \mathrm{~A}$ (4) upon addition of SAM. Formation of the L-cluster was monitored by the appearance of an L-cluster-specific $\mathrm{S}=1 / 2$ signal at $g=1.94$ (dashed vertical line). All protein samples have a concentration of $15 \mathrm{mg} \mathrm{mL}^{-1}$. The EPR spectra were recorded at $5 \mathrm{~mW}$ and $20 \mathrm{~K}$. $\mathbf{b} \mathrm{M}$-cluster maturation

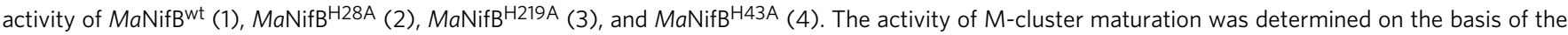
$\mathrm{C}_{2} \mathrm{H}_{2}$-reducing activity of reconstituted NifDK, using SAM-treated MaNifB proteins as the M-cluster sources. The EPR analysis was performed three times independently ( $n=3$ independent samples), and representative results are shown in (a). The maturation assay was performed five times independently ( $n=5$ independent samples), and data are presented as mean \pm S.D. (b). See Methods for the detailed composition of maturation assays.

The role of histidine ligand in L-cluster maturation. Continuous wave $(\mathrm{CW}) \mathrm{EPR}$ analysis provided the first insights into the function of $\mathrm{His}^{43}$ in the cofactor core assembly process. Consistent with the coupling and rearrangement of the K1- and K2-clusters into an L-cluster, an L-cluster-specific, $g=$ 1.94 signal $^{9,10,15}$ is observed in the spectra of $M a \mathrm{NifB}^{\mathrm{wt}}, \mathrm{MaN}$ if ${ }^{\mathrm{H} 28 \mathrm{~A}}$, and $M a \mathrm{NifB}^{\mathrm{H} 219 \mathrm{~A}}$ upon incubation of these proteins with SAM (Fig. 2a, traces 1-3). In contrast, the $g=1.94$ signal is absent from the spectrum of $M a \mathrm{NifB}^{\mathrm{H} 43 \mathrm{~A}}$ following the same treatment, suggesting a lack of K- to L-cluster transformation on this protein after incubation with SAM (Fig. 2a, trace 4). In support of this assignment, the SAM-treated $\mathrm{MaNifB}$ wt, $M a \mathrm{~N}$ $\mathrm{ifB}^{\mathrm{H} 28 \mathrm{~A}}$, and $M a \mathrm{NifB}^{\mathrm{H} 219 \mathrm{~A}}$ can be used as M-cluster sources for the subsequent reconstitution and activation of apo-NifDK in an in vitro assay; whereas the SAM-treated $M a N_{i f B}{ }^{H 43 A}$ cannot support the reconstitution and activation of apo-NifDK in the same assay (Fig. 2b). Interestingly, the activity of $M a \mathrm{NifB}^{\mathrm{H}} 28 \mathrm{~A}$ in this assay is $\sim 41 \%$ less than those of $M a \mathrm{NifB}^{\mathrm{wt}}$ and $M a \mathrm{NifB}^{\mathrm{H}} 219 \mathrm{~A}$, suggesting a possible involvement of $\mathrm{His}^{28}$ in the $\mathrm{K}$ - to L-cluster conversion due to the extremely close location of this residue to one of the Cys ligands $\left(\mathrm{Cys}^{30}\right)$ of the K1-cluster in the primary sequence (see Supplementary Fig. 1b) and, consequently, the tertiary structure of NifB. More importantly, the abolished activity of in $M a \mathrm{NifB}^{\mathrm{H} 43 \mathrm{~A}}$ in the $\mathrm{K}$ - to L-cluster transformation points to a critical role of $\mathrm{His}^{43}$ in coupling the K1- and K2clusters into an $8 \mathrm{Fe} \mathrm{L}$-cluster. 

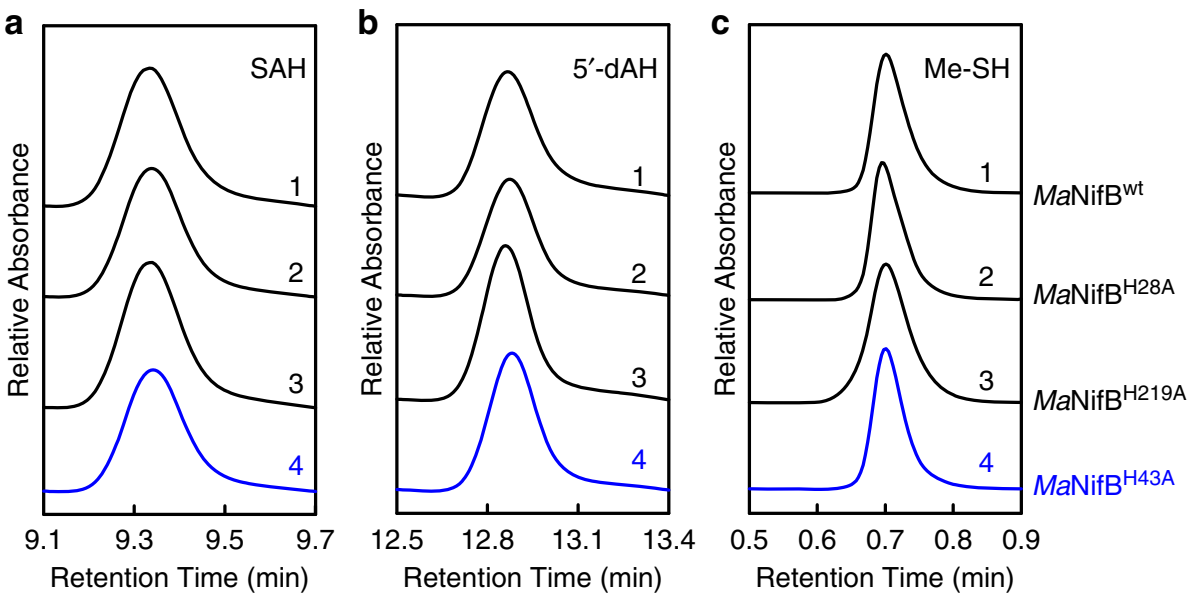

Fig. 3 Functional properties of MaNifB proteins. a, b HPLC elution profiles of SAH (a) and 5'-dAH (b) upon incubation of SAM with MaNifBwt (1), $\mathrm{MaNifB} H 28 \mathrm{~A}$ (2), MaNifB ${ }^{\mathrm{H} 219 \mathrm{~A}}$ (3), and $\mathrm{MaNifB}^{\mathrm{H} 43 \mathrm{~A}}$ (4). c GC analyses of methanethiol (Me-SH) formation upon acid quenching of incubation mixtures containing SAM and MaNifBwt (1), MaNifBH28A (2), MaNifBH219A (3), and MaNifBH43A (4). All products were identified using standards ${ }^{13,14}$. The HPLC (a, b) and GC (c) experiments were each performed three times independently ( $n=3$ independent samples), and representative results are shown in the figure. The protein and SAM concentrations are $0.4 \mathrm{mM}$ and $4 \mathrm{mM}$, respectively, in (a, b); and $40 \mu \mathrm{M}$ and $0.3 \mathrm{mM}$, respectively, in (c). See Methods for detailed compositions of these assays.

To further explore the role of $\mathrm{His}^{43}$ in this process, high performance liquid chromatography (HPLC) was performed to examine the products generated upon incubation of $M a \mathrm{NifB}^{\mathrm{H}} 43 \mathrm{~A}$ with SAM. Like $M a \mathrm{NifB}^{\mathrm{wt}}, \mathrm{MaNifB}^{\mathrm{H} 28 \mathrm{~A}}$, and $M a \mathrm{NifB}^{\mathrm{H} 219 \mathrm{~A}}$ (Fig. 3a, b, traces 1-3), $M a \mathrm{NifB}^{\mathrm{H} 43 \mathrm{~A}}$ (Fig. 3a, b, trace 4) can cleave SAM into S-adenosyl-L-homocysteine (SAH) and 5'deoxyadenosine $\left(5^{\prime}-\mathrm{dAH}\right)$. In addition, as observed in the cases of $M a \mathrm{NifB}^{\mathrm{wt}}, \mathrm{MaNifB}{ }^{\mathrm{H} 28 \mathrm{~A}}$, and $M a \mathrm{NifB}^{\mathrm{H} 219 \mathrm{~A}}$ (Fig. 3c, traces 1-3), formation of methanethiol is detected upon acid quench of an incubation mixture of $M a \mathrm{NifB}^{\mathrm{H} 43 \mathrm{~A}}$ and SAM (Fig. 3c, trace 4). This observation is not particularly surprising because our previous study demonstrates that $\mathrm{SAH}, 5^{\prime}-\mathrm{dAH}$ and methanethiol can be generated as long as both SAM- and K2-clusters are present, even in absence of the K1-cluster. The fact that substitution of the K1-specific ligand, $\mathrm{His}^{43}$, with Ala does not impact the reactivities associated with the SAM- and K2-clusters is consistent with this observation and places the perturbation of the $\mathrm{K}$ - to L-cluster conversion by this substitution after the hydrogen atom abstraction from the K2-associated methyl group (see Supplementary Fig. 1a).

Dual actions of histidine ligand in L-cluster maturation. X-ray absorption spectroscopy (XAS)/extended $\mathrm{x}$-ray absorption fine structure (EXAFS) analysis provided further insights into the role of $\mathrm{His}^{43}$ in L-cluster maturation. XAS/EXAFS analysis has proven to be a valuable tool for obtaining structural information of the cluster species related to the function and assembly of nitrogenase, and previous studies of the wildtype and variant $M a \mathrm{NifB}$ proteins have established XAS/EXAFS parameters that can be used in combination with the EPR and biochemical data to conclusively assign cluster species and monitor cluster transformation in this protein. The $\mathrm{x}$-ray absorption near edge structure (XANES) data reveal a K-edge energy for $M a \mathrm{NifB}^{\mathrm{H} 43 \mathrm{~A}}$ similar to that for $\mathrm{MaN}$ ifB $^{\text {wt }}$ before or after incubation with SAM (Fig. 4a), suggesting a similar sulfur-rich environment in all these protein species ${ }^{16}$. The pre-edge feature of $M a \mathrm{NifB}^{\mathrm{H} 43 \mathrm{~A}}$ is also similar in intensity to that of $M a \mathrm{NifB}^{\mathrm{wt}}$ before incubation with SAM; however, its amplitude does not increase as much as that of $M a \mathrm{NifB}^{\mathrm{wt}}$ upon incubation with SAM (Table 1), suggesting that the transition metal center in SAM-treated $M a \mathrm{NifB}^{\mathrm{H}} 43 \mathrm{~A}$ (designated $M a \mathrm{NifB}^{\mathrm{H}} 43 \mathrm{~A} / \mathrm{SAM}$ ) is less distorted away from centrosymmetry ${ }^{23,24}$ than that in SAM-treated
$M a \mathrm{NifB}^{\mathrm{wt}}$ (designated $M a \mathrm{NifB}{ }^{\mathrm{wt}} / \mathrm{SAM}$ ). Consistent with this observation, the smoothed second derivative of the pre-edge data of $M a \mathrm{NifB}^{\mathrm{wt}} / \mathrm{SAM}$ transitions from a single inverted peak at $\sim 7112.6 \mathrm{eV}$ to two inverted peaks at $\sim 7112.6 \mathrm{eV}$ and $\sim 7114.5 \mathrm{eV}$, respectively (Fig. $4 \mathrm{~b}$ ). Such a change has been attributed to the conversion of the K-cluster (with typical tetrahedral Fe-site geometrie ${ }^{25}$ ) to an L-cluster (with an unusual intermediate geometry between tetrahedral and trigonal pyramidal ${ }^{25}$ ) in $\mathrm{MaNifB}^{\mathrm{wt}}$ upon incubation with $\mathrm{SAM}^{16}$. In the case of $M a \mathrm{NifB}^{\mathrm{H} 43 \mathrm{~A}}$, while a similar peak at $\sim 7112.6 \mathrm{eV}$ is observed in the second derivative before and after incubation with SAM, the line-shapes of these plots beyond $7113 \mathrm{eV}$ are different than those of the corresponding $M a \mathrm{NifB}^{\mathrm{wt}}$ species (Fig. 4b). More importantly, the second peak at $~ 7114.5 \mathrm{eV}$ is absent from the plot of $M a \mathrm{NifB}^{\mathrm{H} 43 \mathrm{~A}} / \mathrm{SAM}$, although $M a \mathrm{~N}$ ifB $^{\mathrm{H} 43 \mathrm{~A}} / \mathrm{SAM}$ seems to undergo a transition analogous to that of $M a \mathrm{NifB}^{\mathrm{wt}} / \mathrm{SAM}$ on the basis of the similar line-shapes of their second derivative plots (Fig. 4b).

Extended X-ray absorption fine structure (EXAFS) analysis of the Fe K-edges of $M a \mathrm{NifB}^{\mathrm{H}} 43 \mathrm{~A}$ provided important insights into the structural metrics of its associated cluster species. Prior to SAM treatment, $M a \mathrm{NifB}^{\mathrm{H} 43 \mathrm{~A}}$ and $M a \mathrm{NifB}^{\text {wt }}$ display two similar features at $\mathrm{R}+\Delta \sim 1.7$ and $2.4 \AA$, respectively, in the Fourier transforms (FT; Fig. 4c) of their EXAFS data (Fig. 4d), although the feature of $M a N_{i f B}{ }^{H 43 A}$ at $\mathrm{R}+\Delta \sim 2.4 \AA$ is much more prominent than that of $M a \mathrm{NifB}^{\mathrm{wt}}$. For $\mathrm{MaNifB}{ }^{\mathrm{H}} 3 \mathrm{~A}$, these FT features can be best fit with $\mathrm{Fe}-\mathrm{S}$ and $\mathrm{Fe}$... Fe scatterers at 2.29 and $2.71 \AA$, respectively; whereas for $M a \mathrm{NifB}^{\mathrm{wt}}$, they are best fit with Fe-S scatterers at $2.29 \AA$ and Fe...Fe scatterers at 2.51 and $2.69 \AA$, respectively (Table 2). Upon incubation with SAM, $M a \mathrm{NifB}^{\mathrm{H} 43 \mathrm{~A}} / \mathrm{SAM}$ and $M a \mathrm{NifB}^{\mathrm{wt}} / \mathrm{SAM}$ seemingly undergo similar changes, both showing extra FT features at $\mathrm{R}+\Delta \sim 3.0$ and $\sim 3.5 \AA$; yet, while $M a \mathrm{NifB}{ }^{\mathrm{wt}} / \mathrm{SAM}$ displays a substantially increased intensity and a clear shift of its FT feature at $\mathrm{R}+\Delta \sim 2.4 \AA$, the corresponding FT feature of $M a \mathrm{NifB}^{\mathrm{H}} 43 \mathrm{~A} / \mathrm{SAM}$ remains largely unchanged (Fig. 4c). The differences between the two SAM-treated MaNifB species are clearly illustrated in the best fits of their EXAFS data: $M a \mathrm{NifB}^{\mathrm{H} 43 \mathrm{~A}} / \mathrm{SAM}$ is best modeled with two types of $\mathrm{Fe}-\mathrm{S}$ scatterers at 2.27 and $3.88 \AA$, respectively, and one type of $\mathrm{Fe}-\ldots \mathrm{Fe}$ scatterers at $2.69 \AA$; whereas $M a \mathrm{NifB}^{\mathrm{wt}} / \mathrm{SAM}$ is best modeled with one type of $\mathrm{Fe}-\mathrm{S}$ scatterers at $2.23 \AA$ and two types of $\mathrm{Fe}$...Fe scatterers at 2.64 and $3.70 \AA$, respectively (Table 2). Most notably, the long-range $\mathrm{Fe} \cdot . \cdot \mathrm{Fe}$ distance at $3.70 \AA$, which originates from the intercubane scattering between the six carbide-coordinated 
a

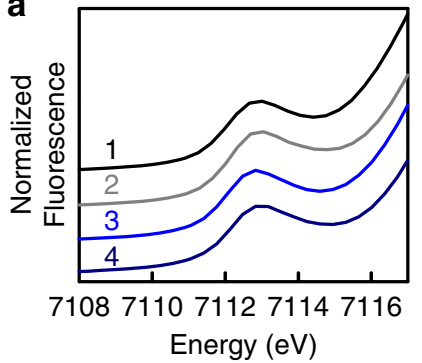

b

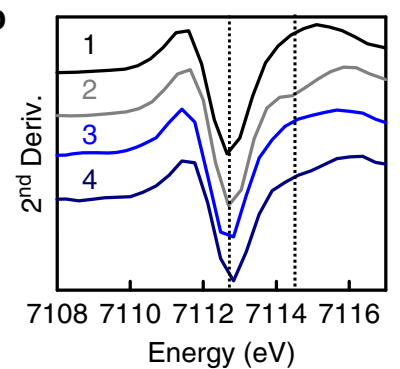

c

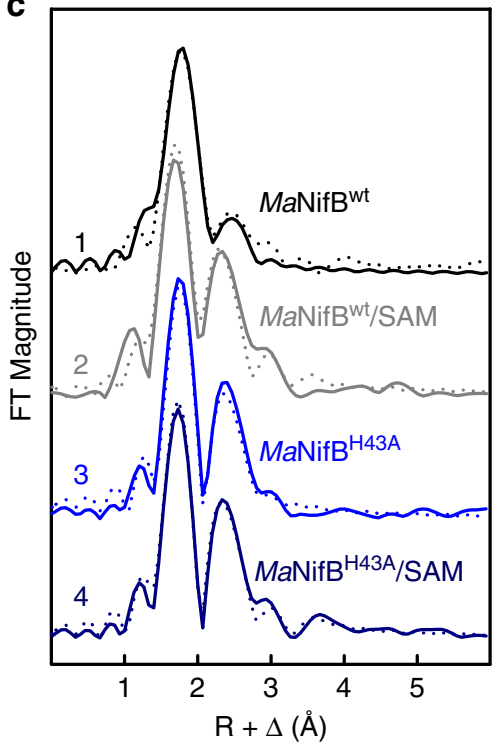

c

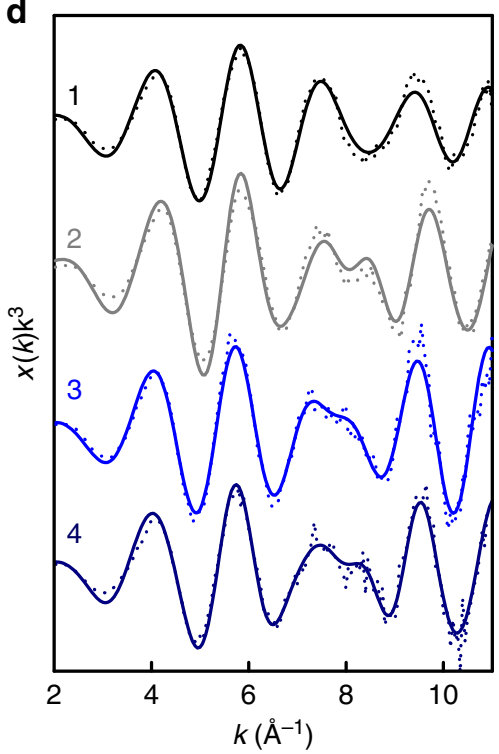

Fig. 4 Fe K-edge XAS analysis of MaNifB proteins. a Pre-edge regions of the normalized fluorescence spectra and (b) smoothed second derivatives of the pre-edge regions, (c) Fourier transforms of the EXAFS data (dotted) and the best fits of data (solid), and (d) $k^{3}$-weighted EXAFS data (dotted) and the best fits of data (solid). Spectra are shown for MaNifBwt before (1) and after (2, designated MaNifBwt/SAM) incubation with SAM, and MaNifBH43A before (3) and after (4, designated MaNifB ${ }^{443 A} / \mathrm{SAM}$ ) incubation with SAM. Note that MaNifBwt carries the K-cluster (a $\left[\mathrm{Fe}_{4} \mathrm{~S}_{4}\right]$ cluster pair); whereas MaNifBwt/ SAM carries the $\mathrm{L}$-cluster $\left(\left[\mathrm{Fe}_{8} \mathrm{~S}_{9} \mathrm{C}\right]\right)$. The peaks at $\sim 7112.6 \mathrm{eV}$ and $\sim 7114.5 \mathrm{eV}$ of the pre-edge regions are indicated by dashed vertical lines to illustrate the transition from a single peak at $\sim 7112.6 \mathrm{eV}$ to two peaks at $\sim 7112.6 \mathrm{eV}$ and $\sim 7114.5 \mathrm{eV}$ in the spectrum of MaNifBwt (b, 1 vs. a, 2), which corresponds to conversion of the K-cluster to an L-cluster upon incubation of MaNifB ${ }^{\text {wt }}$ with SAM. Such a change is not observed in the case of MaNifB ${ }^{\mathrm{H} 43 \mathrm{~A}}$ following the same treatment with SAM (b, 3 vs. a, 4). The XAS analysis was performed three times independently ( $n=3$ independent samples), and representative results are shown in the figure. All protein samples have a concentration of $50 \mathrm{mg} \mathrm{mL}^{-1}$. All scans were taken at $\sim 10 \mathrm{~K}$. See Supporting Information for more details of EXAFS fits.

Table 1 XANES analysis of the Fe K-edge EXAFS data.

\begin{tabular}{|c|c|c|c|}
\hline Protein $^{a}$ & $\begin{array}{l}\text { K-edge } \\
\text { eV }\end{array}$ & $\begin{array}{l}\text { Pre-edge area } \\
\text { units }\end{array}$ & $\begin{array}{l}\text { Pre-edge peak } \\
\text { eV }\end{array}$ \\
\hline$M a \mathrm{NifB}^{w t}$ & 7117.9 & 21.3 & 7112.8 \\
\hline MaNifBwt/SAM & 7118.1 & 25.4 & 7112.9 \\
\hline$M a \operatorname{NifB}^{\mathrm{H} 43} \mathrm{~A}$ & 7118.1 & 21.9 & 7112.8 \\
\hline MaNifB ${ }^{H} 43 \mathrm{~A} / \mathrm{SAM}$ & 7118.2 & 22.7 & 7113.0 \\
\hline
\end{tabular}

a Data are fit between 7108 and $7117 \mathrm{eV}$ from the experimental data. Data for MaNifB ${ }^{\mathrm{wt}}$ and MaNifBwt/SAM are taken from Ref. ${ }^{16}$.
Fe atoms at the cofactor core ${ }^{25}$, is present only in $M a \mathrm{NifB}^{\mathrm{wt}} / \mathrm{SAM}$ but absent from $M a \mathrm{NifB}^{\mathrm{H}} 43 \mathrm{~A} / \mathrm{SAM}$. This observation suggests that unlike $M a \mathrm{NifB}^{\mathrm{wt}}, \mathrm{MaNifB}{ }^{\mathrm{H}} 43 \mathrm{~A}$ does not enable the formation of an L-cluster with a $\mu_{6}$-coordinated central carbide in place upon incubation with SAM. In support of this argument, $M a \mathrm{NifB}^{\mathrm{H}} 43 \mathrm{~A}$ carries clusters with short-range $\mathrm{Fe}$...Fe distances that are characteristic of the $\left[\mathrm{Fe}_{4} \mathrm{~S}_{4}\right]$ clusters before and after incubation with SAM (Table 2). However, modeling of the cluster species on $M a \mathrm{NifB}^{\mathrm{H} 43 \mathrm{~A}} / \mathrm{SAM}$, contrary to that of the cluster species on $\mathrm{MaNifB}{ }^{\mathrm{H}} 43 \mathrm{~A}$, requires the inclusion of an extra $\mathrm{Fe}-\mathrm{S}$ distance at $3.88 \AA$ (Table 2) that corresponds to the distance from a sulfide to a $\mathrm{Fe}$ at the opposite vertex of a $\left[\mathrm{Fe}_{4} \mathrm{~S}_{4}\right]$ cluster. The appearance of such a distance is consistent with an increased order of the two Kcluster units (i.e., $\mathrm{K} 1$ and $\mathrm{K} 2$ ), or a further processing of these $\left[\mathrm{Fe}_{4} \mathrm{~S}_{4}\right]$ units into a cluster intermediate between the $\mathrm{K}$ - and Lclusters on $\mathrm{MaNifB}{ }^{\mathrm{H}} 43 \mathrm{~A} / \mathrm{SAM}$; more importantly, it highlights an overall homogeneity of the cluster species on $M a \mathrm{NifB}^{\mathrm{H} 43 \mathrm{~A}} / \mathrm{SAM}$, as this $\mathrm{Fe}-\mathrm{S}$ distance can only be observed when the clusters are wellordered and, therefore, uniform in nature. Overall, the mean squared deviations $\left(\sigma^{2}\right)$ of the $S$ and Fe scatterers are rather small $\left(<5 \times 10^{-3} \AA^{2}\right.$; see Supplementary Tables 1 and 2$)$, which further supports the homogeneity of the cluster species in the $M a \mathrm{NifB}$ proteins. Three most likely configurations can be proposed for this cluster intermediate: (i) a partial $\left[\mathrm{Fe}_{4} \mathrm{~S}_{3}\right]$ cluster pair bridged by two sulfide $\left(\mathrm{S}^{2-}\right)$ atoms and a carbon $\left(\mathrm{CH}_{\mathrm{x}}\right)$ species, (ii) a face-on $\left[\mathrm{Fe}_{4} \mathrm{~S}_{4}\right]$ cluster pair bridged by a $\mathrm{CH}_{x}$ species, and (iii) a vertex-on $\left[\mathrm{Fe}_{4} \mathrm{~S}_{4}\right]$ cluster pair bridged by a $\mathrm{CH}_{\mathrm{x}}$ species, all of which lack the characteristic cofactor core structure that is defined by an interstitial carbide coordinated with six Fe atoms (Supplementary Fig. 4). Given the homogeneity of the cluster species on $M a \mathrm{NifB}^{\mathrm{H}} 43 \mathrm{~A} / \mathrm{SAM}$, it is likely that one of these proposed models will be identified through future structural characterization of this protein.

\section{Discussion}

Formation of a cluster intermediate on the SAM-treated $M a \mathrm{~N}$ ifB ${ }^{\mathrm{H} 43 \mathrm{~A}}$ that is distinct from both the $\mathrm{K}$ - and L-clusters implies that $\mathrm{His}^{43}$ serves as a key structural element and/or reaction component during the process of cofactor core formation on $M a \mathrm{NifB}$. The substantially increased intensity of the FT feature of $M a \mathrm{NifB}^{\mathrm{H} 43 \mathrm{~A}}$ at $\mathrm{R}+\Delta \sim 2.4 \AA$ relative to that in $M a \mathrm{NifB}^{\mathrm{wt}}$ prior to incubation with SAM (see Fig. 4c) points to a much stronger $\mathrm{Fe}$...Fe scattering that results from a much closer distance between the two $\left[\mathrm{Fe}_{4} \mathrm{~S}_{4}\right]$ units of the K-cluster in $M a \mathrm{NifB}^{\mathrm{H}} 43 \mathrm{~A}$ than those in $M a N_{i f B}{ }^{w t}$. Such a change in the distance and/or orientation of the K1-cluster relative to that of the $\mathrm{K} 2$-cluster apparently presents a challenge for $M a \mathrm{NifB}^{\mathrm{H} 43 \mathrm{~A}}$ to initiate a proper coupling between the two K-cluster units. The $\mathrm{His}^{43}$ ligand, therefore, could play a steric role in keeping the two K-cluster units in the correct distance/orientation to each other by either indirectly pulling the K1-cluster away from the K2-cluster via its ligand capacity or directly separating the K1- and K2-clusters with its bulky imidazole ring (Supplementary Fig. 4, (1)). Additionally, 
Table 2 Best fits of the Fe K-edge EXAFS data.

\begin{tabular}{|c|c|c|c|c|c|c|c|c|c|}
\hline Protein ${ }^{a}$ & \multicolumn{3}{|c|}{ Fe-S } & \multicolumn{3}{|c|}{ Fe•••Fe } & \multicolumn{3}{|c|}{ Fe•••Fe } \\
\hline MaNifBwt & 3.8 & 2.29 & 8.19 & 1 & 2.51 & 5.82 & 1.5 & 2.69 & 4.35 \\
\hline $\mathrm{MaNifB}{ }^{\mathrm{H} 43 \mathrm{~A}}$ & 3 & 2.29 & 2.98 & 2 & 2.71 & 4.02 & - & - & - \\
\hline \multirow[t]{2}{*}{$\mathrm{MaNifB}{ }^{\mathrm{H} 43 \mathrm{~A}} / \mathrm{SAM}$} & 3 & 2.27 & 4.18 & 2 & 2.69 & 4.19 & - & - & - \\
\hline & 1 & 3.88 & 1.53 & - & - & - & - & - & - \\
\hline
\end{tabular}

given our observation of a loss of the nitrogen ligand upon conversion of the $\mathrm{K}$-cluster to an L-cluster on $\mathrm{MaNifB}{ }^{11}$, $\mathrm{His}^{43}$ may lose its coordination to the K1-cluster via protonation, thereby freeing up $\mathrm{K} 1$ for the subsequent coupling with $\mathrm{K} 2$ into an L-cluster, and facilitating the release of the completed L-cluster to the next biosynthetic apparatus for further maturation. As such, $\mathrm{His}^{43}$ likely functions as a molecular switch via reversible protonation and deprotonation events, securing the cluster in place in its deprotonated state while giving the cluster certain structural flexibility in its protonated state to accommodate the different states required for cluster conversion. A similarly labile nitrogen ligand is also found in mitoNEET, where protonation of a His ligand to a $\left[\mathrm{Fe}_{2} \mathrm{~S}_{2}\right]$ cluster permits transfer of the cluster to downstream acceptor proteins ${ }^{26,27}$.

In light of this proposal, it is interesting to consider a coupling of the function of $\mathrm{His}^{43}$ as a molecular switch with another role of this residue in cofactor core formation, one that is involved in the further deprotonation/dehydrogenation of the initial methylene radical to yield the interstitial carbide at the center of the L-cluster. The observation that the two K-cluster units in SAM-treated $M a \mathrm{NifB}^{\mathrm{H} 43 \mathrm{~A}}$ become more aligned with each other but remain largely separate FeS cubanes in character (Supplementary Fig. 4, (2)) is consistent with an interruption of the carbide formation/insertion process that is required for the coupling/rearrangement of $\mathrm{K} 1$ and $\mathrm{K} 2$ into the geometry of a cofactor core. Consequently, the cluster is rendered in an unfinished state with the carbon intermediate $\left(\mathrm{CH}_{x}\right)$ not fully deprotonated or dehydrogenated and attached to one or both of the K-cluster units (Supplementary Fig. 4, (3). It is important to note that, other than $\mathrm{His}^{43}$, additional residues may also be involved in processing the carbon intermediate to an interstitial carbide, as substitution of $\mathrm{His}^{28}$ with Ala apparently reduces the efficiency of L-cluster formation on NifB by $41 \%$ (see Fig. 2 b). A proton relay mechanism involving multiple histidine (or equivalent) residues may be employed in this case to facilitate efficient deprotonation/dehydrogenation of the initial methylene radical to eventually yield a carbide in the center of the Lcluster. While the role of $\mathrm{His}^{43}$ and other relevant players in the cofactor core formation process is yet to be elucidated, the results of this study provide an important framework for further investigations into the unique radical chemistry underlying the formation of the core structure of the nitrogenase cofactor. Knowledge obtained from these studies will contribute to a better understanding of the mechanism of nitrogenase and shed important light on the mechanisms of analogous biological systems.

\section{Methods}

General information. Unless otherwise specified, all chemicals were purchased from Sigma-Aldrich (St. Louis, MO) and Thermo Fisher Scientific (Waltham, MA), and all experiments were performed under an Ar atmosphere using Schlenk techniques and a glove box operating at $<3 \mathrm{ppm}_{2}$.
Cell growth and protein purification. E. coli strains expressing His-tagged $M a \mathrm{NifB}^{\mathrm{wt}}$ (strain YM114EE), MaNifB ${ }^{\mathrm{H} 28 \mathrm{~A}}$ (strain YM242EE), MaNifB ${ }^{\mathrm{H} 43 \mathrm{~A}}$ (strain YM244EE), MaNifB ${ }^{\mathrm{H} 219 \mathrm{~A}}$ (strain YM246EE), $M a \mathrm{NifB}^{\mathrm{K} 1}$ (strain YM165EE) and $\mathrm{MaNifB}{ }^{\mathrm{K} 1-\mathrm{H} 43 \mathrm{~A}}$ (strain YM307EE) were grown in $10-\mathrm{L}$ batches in Difco $\mathrm{LB}$ medium containing $100 \mathrm{mg} \mathrm{L}^{-1}$ ampicillin (BD Biosciences) in a BIOFLO 415 fermenter (New Brunswick Scientific) at $37^{\circ} \mathrm{C}$, with $200 \mathrm{rpm}$ agitation and $10 \mathrm{~L}^{\wedge} \mathrm{min}^{-1}$ airflow. When $\mathrm{OD}_{600}$ reached 0.5 , the temperature was lowered to $25^{\circ} \mathrm{C}$ before expression of the wildtype and variant $M a \mathrm{NifB}$ proteins was induced by addition of $25 \mu \mathrm{M}$ IPTG. Expression of proteins was allowed to continue for $16 \mathrm{~h}$ before cells were harvested by centrifugation using a Thermo Fisher Scientific Legend XTR centrifuge. Subsequently, His-tagged $M a N i f B$ proteins were purified by immobilized metal affinity chromatography (IMAC) ${ }^{9,10}$.

SDS-PAGE analysis. The purified wildtype and variant $M a \mathrm{NifB}$ proteins were subjected to sodium dodecyl sulfate-polyacrylamide gel electrophoresis (SDSPAGE) analysis on a $4-20 \%$ precast Tris-glycine gel (Bio-Rad).

Iron determination. The iron contents of the FeS-reconstituted wildtype and variant $M a \mathrm{NifB}$ proteins were determined by inductively coupled plasma optical emission spectroscopy (ICP-OES) using a Thermo Scientific iCAP7000. Stock solutions of elemental iron ( $1 \mathrm{mg} \mathrm{mL}^{-1}$, Inorganic Ventures) were diluted to make standard solutions for calibration. Each protein sample was mixed with $100 \mu \mathrm{L}$ concentrated sulfuric acid $\left(\mathrm{H}_{2} \mathrm{SO}_{4}\right)$ and $100 \mu \mathrm{L}$ concentrated nitric acid $\left(\mathrm{HNO}_{3}\right)$ and heated at $250{ }^{\circ} \mathrm{C}$ for $30 \mathrm{~min}$. This procedure was repeated until the solutions became colorless. The solution was then cooled to room temperature and diluted to a total volume of $10 \mathrm{~mL}$ with $2 \% \mathrm{HNO}_{3}$ prior to sample analysis.

FeS cluster reconstitution. The purified wildtype or variant $M a \mathrm{NifB}$ was treated with $20 \mathrm{mM}$ bathophenanthroline disulfonate, an iron chelator, in a buffer containing $2 \mathrm{mM}$ dithionite (DT; $\left.\mathrm{Na}_{2} \mathrm{~S}_{2} \mathrm{O}_{4}\right), 50 \mathrm{mM}$ Tris- $\mathrm{HCl}(\mathrm{pH} 8.0)$ and $500 \mathrm{mM}$ $\mathrm{NaCl}$, followed by incubation at room temperature for $1 \mathrm{~h}$ to remove the endogenous FeS clusters associated with the protein. Subsequently, this mixture was diluted with a buffer containing $50 \mathrm{mM}$ Tris- $\mathrm{HCl}(\mathrm{pH} \mathrm{8.0)}$ and loaded on a $\mathrm{Q}$ Sepharose column (GE Healthcare). The column was then washed with a buffer containing $2 \mathrm{mM}$ DT, $50 \mathrm{mM}$ Tris- $\mathrm{HCl}(\mathrm{pH} 8.0)$ and $50 \mathrm{mM} \mathrm{NaCl}$ prior to elution of the MaNifB protein with a buffer containing $50 \mathrm{mM}$ Tris- $\mathrm{HCl}(\mathrm{pH} 8.0)$ and $500 \mathrm{mM} \mathrm{NaCl}$. Dithionite was removed by running protein through a Sephadex G-25 (GE Healthcare) column equilibrated with $50 \mathrm{mM}$ Tris- $\mathrm{HCl}$ (pH 8.0) and $10 \%$ glycerol. Reconstitution of the wildtype or variant $M a \mathrm{NifB}$ protein with synthetic $\left[\mathrm{Fe}_{4} \mathrm{~S}_{4}\right]$ clusters ${ }^{15}$ was carried out by adding a dimethylformamide (DMF) solution of synthetic $\left[\mathrm{Fe}_{4} \mathrm{~S}_{4}\right]$ cluster dropwise at a molar ratio of 5:1 to the MaNifB protein in a buffer containing $20 \mathrm{mM} \beta$-mercaptoethanol and $50 \mathrm{mM}$ Tris- $\mathrm{HCl}$ ( $\mathrm{pH}$ 8.0), with continuous stirring on ice. After incubation on ice for $1 \mathrm{~h}$, the reaction mixture was diluted with a buffer containing $2 \mathrm{mM}$ DT and $50 \mathrm{mM}$ Tris$\mathrm{HCl}(\mathrm{pH} \mathrm{8.0)}$ and loaded on a Q Sepharose column. The column was then washed with a buffer containing $2 \mathrm{mM} \mathrm{DT}, 50 \mathrm{mM}$ Tris- $\mathrm{HCl}$ and $50 \mathrm{mM} \mathrm{NaCl}$ prior to elution of the reconstituted $\mathrm{MaNifB}$ with a buffer containing $2 \mathrm{mM} \mathrm{DT}, 50 \mathrm{mM}$ Tris- $\mathrm{HCl}(\mathrm{pH} 8.0)$ and $500 \mathrm{mM} \mathrm{NaCl}$. Reconstituted wildtype and variant $\mathrm{MaNifB}$ proteins were subjected to metal determination, activity assays and EPR analysis.

Cofactor maturation assays. The cofactor maturation assay contained, in a tota volume of $1.0 \mathrm{~mL}, 25 \mathrm{mM}$ Tris- $\mathrm{HCl}$ (pH 8.0), $20 \mathrm{mM}$ DT, $3.5 \mathrm{mg}$ FeS-reconstituted wildtype or variant $M a \mathrm{NifB}, 10 \mathrm{mM}$ SAM, $2 \mathrm{mg} \Delta n i f B A v \mathrm{NifEN}, 1.4 \mathrm{mg} \mathrm{NifH}$, $0.8 \mathrm{mM}$ ATP, $1.6 \mathrm{mM} \mathrm{MgCl}_{2}, 10 \mathrm{mM}$ creatine phosphate, 8 units creatine phosphokinase, $0.3 \mathrm{mM}$ homocitrate, $0.3 \mathrm{mM} \mathrm{Na} \mathrm{MoO}_{4}$ and $0.5 \mathrm{mg} \Delta$ nifB $A v \mathrm{NifDK}$. This mixture was incubated at $30^{\circ} \mathrm{C}$ for $30 \mathrm{~min}$ before it was examined for enzymatic activities ${ }^{9,10}$.

S-adenosyl-L-methionine (SAM) cleavage assays. The SAM cleavage assay contained, in a total volume of $0.3 \mathrm{~mL}, 25 \mathrm{mM}$ Tris- $\mathrm{HCl}(\mathrm{pH} 8.0), 5 \%$ glycerol $(\mathrm{v} / \mathrm{v}), 40 \mu \mathrm{M}$ wildtype or variant $\mathrm{MaNifB}$, and $0.3 \mathrm{mM}$ SAM. Assays were incubated 
at $25^{\circ} \mathrm{C}$ for $60 \mathrm{~min}$ with intermittent mixing, before they were terminated by filtration through Amicon Ultra 30,000 MWCO centrifugal filters. Samples were then supplemented by trifluoroacetic acid (TFA) to a concentration of $0.14 \%$ before being analyzed by a Thermo Scientific Dionex Ultimate 3000 UHPLC system equipped with an Acclaim $120 \mathrm{C} 18$ column $(4.6 \times 100 \mathrm{~mm}, 5-\mu \mathrm{m}$ particle size). The flow rate of buffer was $0.5 \mathrm{~mL}^{\wedge} \mathrm{min}^{-1}$, and the column was kept at $30^{\circ} \mathrm{C}$. The column was equilibrated with $98 \%$ buffer $\mathrm{A}\left(50 \mathrm{mM} \mathrm{KH}_{2} \mathrm{PO}_{4}, \mathrm{pH} 6.6\right)$ and $2 \%$ buffer B (100\% methanol) before each injection of a $100-\mu \mathrm{L}$ sample. After sample injection, a linear gradient of $2-60 \%$ buffer B was applied over $20 \mathrm{~min}$, followed by 8 min of isocratic flow with $60 \%$ buffer B and a linear gradient of $60-2 \%$ buffer B over $4 \mathrm{~min}$. Elution of products was monitored at a UV wavelength of $254 \mathrm{~nm}$. After each run, the column was equilibrated for 5 min with $2 \%$ buffer B before the injection of the next sample.

Acid quench experiments. Detection of $M a \mathrm{NifB}$-dependent production of methanethiol was performed ${ }^{14}$. First, excess DT was removed from wildtype and variant $M a N i f B$ via gel filtration with Sephadex G-25 fine resin that was equilibrated with a buffer containing $25 \mathrm{mM}$ Tris- $\mathrm{HCl}(\mathrm{pH}$ 8.0). Immediately following the removal of excess reductant, $40 \mathrm{nmol}$ of $M a \mathrm{NifB}$ was added to a sealed $300-\mu \mathrm{L}$ glass vial that contained $400 \mathrm{nmol}$ SAM in a total volume of $100 \mu \mathrm{L}$. These $100-\mu \mathrm{L}$ reactions were then incubated for $30 \mathrm{~min}$ at $25^{\circ} \mathrm{C}$ before being quenched by $25 \mu \mathrm{L}$ of $1 \mathrm{M} \mathrm{HCl}$. To observe the formation of the volatile methanethiol, the acidquenched samples were incubated at $60{ }^{\circ} \mathrm{C}$ for $15 \mathrm{~min}$ and equilibrated to room temperature for $10 \mathrm{~min}$ before the entire headspace was injected by a gas-tight syringe onto a GC-MS (Thermo-Fisher Scientific Trace 1300 GC connected to a Thermo-Fisher Scientific ISQ QD single quadrupole mass spectrometry) with a Restek Rxi-1ms column ( $30 \mathrm{~m}, 0.32 \mathrm{~mm}$ ID, $4.0 \mu \mathrm{m} \mathrm{df})$. The GC inlet and oven temperatures were maintained at $30^{\circ} \mathrm{C}$, while the mass spectrometry transfer line and ion source were maintained at $250^{\circ} \mathrm{C}$. Total ion chromatograms were generated under SIM conditions in electron ionization mode, and methanethiol was detected at an $m / z$ ratio of 47 . The base peaks were selected on the basis of the characterization of standard samples (Sigma-Aldrich) under full scan conditions and comparison to those reported in the National Institute of Standards and Technology database.

\section{Electron paramagnetic resonance (EPR) analysis. Sample preparation was} carried out in a Vacuum Atmospheres glove box with less than $1 \mathrm{ppm} \mathrm{O}_{2}$ and flash frozen in liquid nitrogen before analysis. The dithionite-reduced samples were prepared by incubating $50 \mu \mathrm{M}$ wildtype or variant $M a \mathrm{NifB}$ with $40 \mathrm{mM}$ SAM for $15 \mathrm{~min}$, followed by re-isolation of $\mathrm{MaNifB}$ into a buffer containing $50 \mathrm{mM}$ Tris$\mathrm{HCl}$ ( $\mathrm{pH} 8.0$ ), $500 \mathrm{mM} \mathrm{NaCl}$, and $2 \mathrm{mM}$ dithionite (DT). The indigo disulfonate (IDS)-oxidized samples were prepared by incubating the re-isolated $\mathrm{MaNifB}$ with excess IDS for $5 \mathrm{~min}$, followed by removal of excess IDS was using a Sephadex G-25 desalting column. The DT-reduced or IDS-oxidized $M a \mathrm{NifB}$ sample was then concentrated to $15 \mathrm{mg} \mathrm{mL}^{-1}$, followed by transfer of the sample into EPR tubes. The samples were then flash frozen and stored in liquid nitrogen. CW EPR spectra were recorded by an ESP $300 \mathrm{E}_{\mathrm{z}}$ spectrophotometer (Bruker) interfaced with an ESR-9002 liquid-helium continuous-flow cryostat (Oxford Instruments) using a microwave power of $5 \mathrm{~mW}$ (IDS-oxidized samples) or $50 \mathrm{~mW}$ (IDT-reduced samples), a gain of $5 \times 10^{4}$, a modulation frequency of $100 \mathrm{kHz}$, and a modulation amplitude of $5 \mathrm{G}$. Five scans was recorded for each sample in perpendicular mode at $20 \mathrm{~K}$ (IDS-oxidized samples) or $10 \mathrm{~K}$ (DT-reduced samples) using a microwave frequency of $9.62 \mathrm{GHz}$.

All pulse EPR studies were carried out at the UC Davis CalEPR center, using a Bruker EleXsys E580 pulse EPR spectrometer equipped with an Oxford-CF935 liquid-helium cryostat and an ITC-503 temperature controller. Pulse data were collected using a Bruker MS5 probe (X-band) or an R.A. Isaacson-designed cylindrical TE011 resonator (Q-band) ${ }^{28}$ adapted for pulse EPR in an Oxford Instruments CF935 cryostat. Three-pulse ESEEM spectra were collected using the pulse sequence $\pi / 2-\tau-\pi / 2-T-\pi / 2-\tau$-echo where the delay time, T, was increased by 16 ns steps. ESEEM spectra were recorded at $10 \mathrm{~K}, \tau=128-144 \mathrm{~ns}$ (values chosen to minimize proton modulations to the spectra), $\pi / 2=12 \mathrm{~ns}$, and a microwave frequency of $9.3366 \mathrm{GHz}$. Spectral processing (subtraction of a background exponential, application of a hamming window, and FFT) were performed using the EasySpin 5.2.27 toolbox in Matlab R2019a ${ }^{29}$.

X-ray absorption spectroscopy (XAS) analysis. The XAS samples were prepared the same way as the EPR samples (see above). The sample concentrations were $50 \mathrm{mg} \mathrm{mL}^{-1}$. Fe K-edge X-ray absorption spectra were collected on SSRL beam line 7-3 using a 30-element solid state Ge detector (Canberra) with a SPEAR3 storage ring current of $\sim 500 \mathrm{~mA}$ at an energy of $3.0 \mathrm{GeV}$. The BL7-3 optics consists of a flat, bent, harmonic rejection vertically collimating Rh-coated $\mathrm{Si} \mathrm{M}_{0}$ mirror and a liquid nitrogen cooled double crystal $\mathrm{Si}(220)$ monochromator. A total of 7 and 6 scans, respectively, were collected for $M a N_{i f B}{ }^{H 43 A}$ before and after incubation with SAM (designated $M a \mathrm{NifB}^{\mathrm{H} 43 \mathrm{~A}}$ and $\mathrm{MaNifB}{ }^{\mathrm{H} 43 \mathrm{~A}} / \mathrm{SAM}$ ). All scans were taken between 6882 and $8000 \mathrm{eV}$ at $\sim 10 \mathrm{~K}$ using an Oxford Instruments CF1208 continuous flow liquid-helium cryostat using a closed-cycle cooled He gas loop. An iron foil was placed in the beam pathway prior to the ionization chamber $I_{0}$ and scanned concomitantly for an energy calibration, with the first inflection point of the edge assigned to $7112.0 \mathrm{eV}$. A Soller slit with a $3 \mu \mathrm{m} \mathrm{Mn}$ filter was used to increase the signal-to-noise ratio of the spectra. Photoreduction was monitored by scanning the same spot on the sample twice and comparing the first derivative peaks associated with the edge energy during data collection.

The detector channels from the scans were examined, calibrated and averaged using EXAFSPAK ${ }^{30}$ and then processed for EXAFS analysis using PYSPLINE ${ }^{31}$ to extract $\chi(k)$. PYSPLINE was used to subtract a second-order background from the entire range of data and subsequently generate a spline function to model background absorption through the EXAFS region. A four-region spline was chosen with 2, 3, 3 order polynomials over the post edge region, and the data were normalized to have an edge jump of 1.0 at $7130 \mathrm{eV}$. Following a modified data analysis protocol ${ }^{25}$, the Fe K-edge EXAFS data for the clusters associated with $M a \mathrm{NifB}^{\mathrm{H} 43 \mathrm{~A}}$ and $M a \mathrm{NifB}^{\mathrm{H} 43 \mathrm{~A}} / \mathrm{SAM}$ were generated by subtracting the $k$-weighted EXAFS data, $\chi(k)$, of $M a \mathrm{NifB}^{\mathrm{SAM}}$ (an $M a \mathrm{NifB}$ variant carrying only the SAMcluster $\left.^{11}\right)$ from the $\chi(k)$ of the samples in a 1:2 ratio on the basis of the proportionate iron quantity for each cluster species (i.e., 4 Fe for the SAM-cluster and $8 \mathrm{Fe}$ for the K-clusters). Theoretical phase and amplitude parameters for a given absorber-scatterer pair were calculated using FEFF $8.40^{32}$ and subsequently applied to the nonlinear least squares Opt fitting program of the EXAFSPAK package during curve fitting. Parameters for each species were calculated using an appropriate model derived from either the crystal structure of the M-cluster in NifDK (PDB code $3 \mathrm{U} 7 \mathrm{Q})^{5}$, where the Mo atom was exchanged for an Fe atom, or from the $\left[\mathrm{Fe}_{4} \mathrm{~S}_{4}\right]$ cluster in NifH (PDB code $\left.1 \mathrm{G} 5 \mathrm{P}\right)^{33}$ because there are no available crystal structures of $\mathrm{MaNifB}$. In all analyses, the coordination number of a given shell $(N)$ was a fixed parameter and was varied iteratively in integer steps, whereas the bond lengths $(R)$ and mean-square deviation $\left(\sigma^{2}\right)$ were allowed to freely float. The estimated uncertainties in $R, \sigma^{2}$, and $N$ are $0.02 \AA, 0.1 \times 10^{-3} \AA^{2}$, and $20 \%$, respectively. The amplitude reduction factor $S_{0}$ was fixed at 1.0 for the Fe K-edge data, whereas the edge-shift parameter $\Delta E_{0}$ was allowed to float as a single value for all shells. Thus, in any given fit, the number of floating parameters was typically equal to $2 \times$ number of shells +1 . The goodness of fit (GOF) parameters were calculated as follows:

$$
\begin{aligned}
F & =\sqrt{\sum k^{6}\left(\chi_{\exp }-\chi_{\text {calc }}\right)^{2}}, \\
F^{\prime} & =\sqrt{\sum k^{6}\left(\chi_{\exp }-\chi_{\text {calc }}\right)^{2} / \sum k^{6}\left(\chi_{\exp }\right)^{2}} .
\end{aligned}
$$

The Fe K-edge data were analyzed with a $k$ range of $2-11.2 \AA^{-1}(\Delta \mathrm{R}=0.17 \AA)$ to allow comparison between previously reported data ${ }^{16}$, although the data could be analyzed with higher resolution with a $k$ range of $2-14 \AA^{-1}$ for $M a \mathrm{NifB}^{\mathrm{H}} 43 \mathrm{~A}$ and $\mathrm{MaNifB} \mathrm{H}^{\mathrm{HA}} / \mathrm{SAM}$. Pre-edge analysis was performed on the Fe K-edge fluorescence data normalized to have an edge jump of 1.0 at $7130 \mathrm{eV}$ in PYSPLINE. The preedge features were fit as described elsewhere ${ }^{23}$ between 7108 and $7117 \mathrm{eV}$ using the Fityk $^{34}$ program with pseudo-Voigt functions composed of 50:50 Gaussian/ Lorentzian functions

Reporting summary. Further information on research design is available in the Nature Research Reporting Summary linked to this article.

\section{Data availibility}

The authors declare that all data supporting the findings of this study are available within the article and its Supplementary Information files and from the corresponding authors upon reasonable request. The National Institute of Standards and Technology database is available at https://www.nist.gov/data. Parameters used for cluster modeling are available at https://www.rcsb.org/ using PDB IDs 3U7Q and 1G5P.

Received: 27 December 2019; Accepted: 19 March 2020; Published online: 09 April 2020

\section{References}

1. Burgess, B. K. \& Lowe, D. J. Mechanism of molybdenum nitrogenase. Chem. Rev. 96, 2983-3012 (1996).

2. Rees, D. C. et al. Structural basis of biological nitrogen fixation. Philos. Trans A: Math. Phys. Eng. Sci. 363, 971-984 (2005).

3. Hoffman, B. M., Lukoyanov, D., Yang, Z. Y., Dean, D. R. \& Seefeldt, L. C. Mechanism of nitrogen fixation by nitrogenase: the next stage. Chem. Rev. 114, 4041-4062 (2014).

4. Einsle, O. et al. Nitrogenase MoFe-protein at $1.16 \AA$ resolution: a centra ligand in the FeMo-cofactor. Science 297, 1696-1700 (2002).

5. Spatzal, T. et al. Evidence for interstitial carbon in nitrogenase FeMo cofactor. Science 334, 940 (2011).

6. Lancaster, K. M. et al. X-ray emission spectroscopy evidences a central carbon in the nitrogenase iron-molybdenum cofactor. Science 334, 974-977 (2011) 
7. Frey, P. A., Hegeman, A. D. \& Ruzicka, F. J. The radical SAM superfamily. Crit. Rev. Biochem. Mol. Biol. 43, 63-88 (2008).

8. Broderick, J. B., Duffus, B. R., Duschene, K. S. \& Shepard, E. M. Radical Sadenosylmethionine enzymes. Chem. Rev. 114, 4229-4317 (2014).

9. Wiig, J. A., Hu, Y. \& Ribbe, M. W. NifEN-B complex of Azotobacter vinelandii is fully functional in nitrogenase FeMo cofactor assembly. Proc. Natl Acad. Sci. U.S.A. 108, 8623-8627 (2011).

10. Fay, A. W., Wiig, J. A., Lee, C. C. \& Hu, Y. Identification and characterization of functional homologs of nitrogenase cofactor biosynthesis protein NifB from methanogens. Proc. Natl Acad. Sci. U.S.A. 112, 14829-14833 (2015).

11. Rettberg, L. A. et al. Probing the coordination and function of $\mathrm{Fe}_{4} \mathrm{~S}_{4}$ modules in nitrogenase assembly protein NifB. Nat. Commun. 9, 2824 (2018).

12. Wilcoxen, J. et al. Electron paramagnetic resonance characterization of three iron-sulfur clusters present in the nitrogenase cofactor maturase NifB from Methanocaldococcus infernus. J. Am. Chem. Soc. 138, 7468-7471 (2016).

13. Wiig, J. A., Hu, Y., Lee, C. C. \& Ribbe, M. W. Radical SAM-dependent carbon insertion into the nitrogenase M-cluster. Science 337, 1672-1675 (2012).

14. Wiig, J. A., Hu, Y. \& Ribbe, M. W. Refining the pathway of carbide insertion into the nitrogenase M-cluster. Nat. Commun. 6, 8034 (2015).

15. Tanifuji, K. et al. Tracing the '9th sulfur' of the nitrogenase cofactor via a semi-synthetic approach. Nat. Chem. 10, 568-572 (2018).

16. Jasniewski, A. J. et al. Spectroscopic characterization of an eight-iron nitrogenase cofactor precursor that lacks the '9th sulfur'. Angew. Chem. Int Ed. Engl. 58, 14703-14707 (2019).

17. Hu, Y. et al. FeMo cofactor maturation on NifEN. Proc. Natl Acad. Sci. U.S.A. 103, 17119-17124 (2006).

18. Yoshizawa, J. M. et al. Optimization of FeMoco maturation on NifEN. J. Am. Chem. Soc. 131, 9321-9325 (2009).

19. Kaiser, J. T., Hu, Y., Wiig, J. A., Rees, D. C. \& Ribbe, M. W. Structure of precursor-bound NifEN: a nitrogenase FeMo cofactor maturase/insertase. Science 331, 91-94 (2011).

20. Fay, A. W. et al. Spectroscopic characterization of the isolated ironmolybdenum cofactor (FeMoco) precursor from the protein NifEN. Angew. Chem. Int. Ed. 50, 7787-7790 (2011).

21. Hu, Y. et al. Nitrogenase Fe protein: a molybdate/homocitrate insertase. Proc. Natl Acad. Sci. U.S.A. 103, 17125-17130 (2006).

22. Schmid, B. et al. Structure of a cofactor-deficient nitrogenase MoFe protein. Science 296, 352-356 (2002).

23. Westre, T. E. et al. A multiplet analysis of Fe K-edge $1 \mathrm{~s} \rightarrow 3 \mathrm{~d}$ pre-edge features of iron complexes. J. Am. Chem. Soc. 119, 6297-6314 (1997).

24. Sarangi, R. X-ray absorption near-edge spectroscopy in bioinorganic chemistry: application to $\mathrm{M}-\mathrm{O}_{2}$ systems. Coord. Chem. Rev. 257, 459-472 (2013).

25. Corbett, M. C. et al. Structural insights into a protein-bound ironmolybdenum cofactor precursor. Proc. Natl Acad. Sci. U.S.A. 103, 1238-1243 (2006).

26. Karmi, O.et al. The unique fold and lability of the[2Fe-2S] clusters of NEET proteins mediate their key functions in health anddisease. J. Biol. Inorg. Chem. 23, 599-612 (2018)

27. Tamir, S. et al. Structure-function analysis of NEET proteins uncovers their role as key regulators of iron and ROS homeostasis in health and disease. Biochim. Biophys. Acta 1853, 1294-1315 (2015).

28. Flores, M. et al. Probing hydrogen bonding to quinone anion radicals by ${ }^{1} \mathrm{H}$ and ${ }^{2} \mathrm{H}$ ENDOR spectroscopy at $35 \mathrm{GHz}$. J. Chem. Phys. 294, 401-413 (2003).

29. Stoll, S. \& Schweiger, A. EasySpin, a comprehensive software package for spectral simulation and analysis in EPR. J. Magn. Reson. 178, 42-55 (2006).

30. George, G. N. in EXAFSPAK: A Suite of Computer Programs for Analysis of Xray Absorption Spectra, https://www-ssrl.slac.stanford.edu/exafspak.html
(Stanford Synchrotron Radiation Laboratory, Stanford Linear Accelerator Center: Menlo Park, CA, 1990).

31. Tenderholt, A., Hedman, B. \& Hodgson, K. O. PySpline: a modern, crossplatform program for the processing of raw averaged XAS edge and EXAFS data. AIP Conf. Proc. 882, 105-107 (2007).

32. Ankudinov, A. L., Ravel, B., Rehr, J. J. \& Conradson, S. D. Real-space multiplescattering calculation and interpretation of X-ray-absorption near-edge structure. Phys. Rev. B 58, 7565-7576 (1998).

33. Strop, P. et al. Crystal structure of the all-ferrous $[4 \mathrm{Fe}-4 \mathrm{~S}] 0$ form of the nitrogenase iron protein from Azotobacter vinelandii. Biochemistry 40, 651-656 (2001)

34. Wojdyr, M. Fityk: a general-purpose peak fitting program. J. Appl. Crystallogr. 43, $1126-1128(2010)$.

\section{Acknowledgements}

This work was supported by NIH-NIGMS grant GM67626 (to M.W.R. and Y.H.) and NIH-NIHGMS grant 1R35GM126961-01 (to R.D.B.).

\section{Author contributions}

L.A.R., J.W., A.J.J., C.C.L., and K.T. performed experiments and analyzed data; J.W., Y.H., R.D.B., and M.W.R. designed experiments, analyzed data, and wrote the manuscript.

\section{Competing interests}

The authors declare no competing interests.

\section{Additional information}

Supplementary information is available for this paper at https://doi.org/10.1038/s41467 020-15627-9.

Correspondence and requests for materials should be addressed to Y.H., R.D.B. or M.W.R.

Peer review information Nature Communications thanks the anonymous reviewer(s) for their contribution to the peer review of this work.

Reprints and permission information is available at http://www.nature.com/reprints

Publisher's note Springer Nature remains neutral with regard to jurisdictional claims in published maps and institutional affiliations.

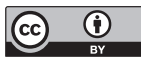

Open Access This article is licensed under a Creative Commons Attribution 4.0 International License, which permits use, sharing, adaptation, distribution and reproduction in any medium or format, as long as you give appropriate credit to the original author(s) and the source, provide a link to the Creative Commons license, and indicate if changes were made. The images or other third party material in this article are included in the article's Creative Commons license, unless indicated otherwise in a credit line to the material. If material is not included in the article's Creative Commons license and your intended use is not permitted by statutory regulation or exceeds the permitted use, you will need to obtain permission directly from the copyright holder. To view a copy of this license, visit http://creativecommons.org/ licenses/by/4.0/

(c) The Author(s) 2020 